\title{
A combined bioinformatics and functional metagenomics approach to discovering lipolytic biocatalysts
}

\author{
Thorsten Masuch ${ }^{1}$, Anna Kusnezowa ${ }^{1}$, Sebastian Nilewski ${ }^{1}$, José T. Bautista ${ }^{2}$, \\ Robert Kourist ${ }^{2}$ and Lars I. Leichert ${ }^{1 *}$
}

\begin{abstract}
${ }^{1}$ Department of Microbial Biochemistry, Institute of Biochemistry and Pathobiochemistry, Ruhr University Bochum, Bochum, Germany, ${ }^{2}$ Junior Research Group for Microbial Biotechnology - Department for Biology and Biotechnology, Ruhr University Bochum, Bochum, Germany
\end{abstract}

\section{OPEN ACCESS}

Edited by:

Weiwen Zhang,

Tianjin University, China

Reviewed by:

Xiangzhen $\mathrm{Li}$

University of Illinois

at Urbana-Champaign, USA

Wolfgang R. Streit,

University of Hamburg, Germany

*Correspondence:

Lars I. Leichert

lars.leichert@ruhr-uni-bochum.de

Specialty section:

This article was submitted to Microbiotechnology, Ecotoxicology

and Bioremediation,

a section of the journal

Frontiers in Microbiology

Received: 31 July 2015

Accepted: 25 September 2015

Published: 13 October 2015

Citation:

Masuch T, Kusnezowa A, Nilewski S,

Bautista JT, Kourist $R$ and Leichert LI

(2015) A combined bioinformatics and functional metagenomics

approach to discovering lipolytic biocatalysts. Front. Microbiol. 6:1110. doi: 10.3389/fmicb.2015.01110
The majority of protein sequence data published today is of metagenomic origin. However, our ability to assign functions to these sequences is often hampered by our general inability to cultivate the larger part of microbial species and the sheer amount of sequence data generated in these projects. Here we present a combination of bioinformatics, synthetic biology, and Escherichia coli genetics to discover biocatalysts in metagenomic datasets. We created a subset of the Global Ocean Sampling dataset, the largest metagenomic project published to date, by removing all proteins that matched Hidden Markov Models of known protein families from PFAM and TIGRFAM with high confidence $\left(E\right.$-value $\left.>10^{-5}\right)$. This essentially left us with proteins with low or no homology to known protein families, still encompassing $\sim 1.7$ million different sequences. In this subset, we then identified protein families de novo with a Markov clustering algorithm. For each protein family, we defined a single representative based on its phylogenetic relationship to all other members in that family. This reduced the dataset to $\sim 17,000$ representatives of protein families with more than 10 members. Based on conserved regions typical for lipases and esterases, we selected a representative gene from a family of 27 members for synthesis. This protein, when expressed in E. coli, showed lipolytic activity toward para-nitrophenyl (pNP) esters. The $K_{m}$-value of the enzyme was $66.68 \mu \mathrm{M}$ for pNP-butyrate and $68.08 \mu \mathrm{M}$ for pNP-palmitate with $k_{\text {cat }} / K_{\mathrm{m}}$ values at $3.4 \times 10^{6}$ and $6.6 \times 10^{5} \mathrm{M}^{-1} \mathrm{~s}^{-1}$, respectively. Hydrolysis of model substrates showed enantiopreference for the R-form. Reactions yielded 43 and $61 \%$ enantiomeric excess of products with ibuprofen methyl ester and 2-phenylpropanoic acid ethyl ester, respectively. The enzyme retains $50 \%$ of its maximum activity at temperatures as low as $10^{\circ} \mathrm{C}$, its activity is enhanced in artificial seawater and buffers with higher salt concentrations with an optimum osmolarity of 3,890 mosmol/l.

Keywords: metagenomics, functional metagenomics, biocatalyst, esterase, lipase

\section{INTRODUCTION}

The global market of industrial enzymes is estimated to have a value between $\$ 4.8$ billion and \$ 5.1 billion and rising (BCC Research, 2014; The Freedonia Group, 2014). The biggest market share falls to hydrolytic enzymes like proteases, amylases, esterases, and lipases (Gupta et al., 2004). Lipolytic enzymes like lipases and esterases are of special interest for the industry, because of their 
various applications in organic chemistry (Jaeger and Eggert, 2002). They are able to economically outcompete some conventional chemical methods, based on their high enantioselectivity, substrate specificity, and mild reaction conditions (Divakar and Manohar, 2007).

Microbial lipolytic enzymes, esterases (EC 3.1.1.1) and lipases (EC 3.1.1.3), are ubiquitous enzymes that hydrolyze organic ester bonds in aqueous solutions. The former hydrolyze small molecules with ester bonds, which are at least partly soluble in water, whereas the latter display a maximum of activity toward long-chained and insoluble triglycerides (Jaeger et al., 1999).

The active site of lipolytic enzymes is a catalytic triad comprised of a nucleophilic serin residue, an acidic residue and a histidin residue (Brady et al., 1990; Lowe, 1992). The structure around the nucleophilic serin residue is called the catalytic elbow with a $\mathrm{G}-\mathrm{x}-\mathrm{S}-\mathrm{x}-\mathrm{G}$ motif, where $\times$ stands for an arbitrary residue. This catalytic elbow is the most conserved structure in this protein family (Mala and Takeuchi, 2008). In some cases the first glycin in this motif can be substituted by alanine, as for example in Lipase A from Bacillus subtilis (Dartois et al., 1992). The socalled oxyanion hole, which occurs in one of three variants: HGx, HGGGx, or Y is another highly conserved feature, by which lipolytic enzymes can be classified (Pleiss et al., 2000; Widmann et al., 2010).

As a result of the steady growth of the biocatalyst market there is a desire for enzymes that can either catalyze the production of new organic compounds through novel reaction pathways or work more efficient in established processes. To accomplish these goals and obtain better biocatalysts known enzymes can be modified via random or targeted mutation. Thus it was possible to modify characteristics like enantioselectivity (Qian and Lutz, 2005), activity and thermal stability (Suen et al., 2004) as well as substrate specificity (Reetz et al., 2005) of lipolytic enzymes.

These procedures need a basis in form of an enzyme which already has promising attributes. Therefore the search for novel enzymes which exhibit such attributes is a worthwhile endeavor. One especially promising prospect for the search for new biocatalysts are metagenomes with their vast amount of genes from non-cultivable bacteria. It is predicted that as few as $1 \%$ of all bacteria can be cultivated under laboratory conditions (Amann et al., 1995), which leaves a huge amount of possibly interesting proteins out of reach of classical genomics (Tringe and Rubin, 2005). DNA from environmental samples is either being sequenced and the sequencing results saved in databases for further investigations via bioinformatics as was done with the results from the Global Ocean Sampling (GOS; Rusch et al., 2007; Yooseph et al., 2007), GOS, or it is transformed into an organism for expression to construct an environmental DNA library which can be screened for the desired activity. The latter has been used frequently to search for novel lipolytic enzymes (e.g., Henne et al., 2000; Lee et al., 2006; Nacke et al., 2011; Berlemont et al., 2013; Mokoena et al., 2013). This method has also been used to discover enzymes from often difficult-tocultivate extremophiles (Rhee et al., 2005; Tirawongsaroj et al., 2008; Levisson et al., 2009). Lipolytic enzymes are probably the most frequent targets of metagenomic expression library screens (Simon and Daniel, 2011). A wide variety of diverse habitats has been examined and lipolytic enzymes could be found in forest soil, marine sediment and water, landfill leachate, and activated sludges, to name just a few examples. Nevertheless, in light of the ever-growing (meta-)genomic sequence information available, one could argue that we have only scratched the surface of the extent of enzyme biodiversity. For a comprehensive list of reported metagenomically derived esterases and lipases see Martínez-Martínez et al. (2013).

A downside of the aforementioned method is the sheer expense of resources that has to be invested into the construction and screening of these environmental gene libraries. Typical studies performed to find novel enzymes can encompass up to 3 million distinct clones (Nacke et al., 2011). Here we present an alternative approach that has the potential to reduce the needed manpower and resources for finding novel enzymes using metagenomic in silico data. This approach uses a bioinformatical arrangement of metagenomic proteins into clusters of high homology, identification of one representative for each cluster and functional annotation based on known structural characteristics of the biocatalyst in question. Using the GOS dataset as a source, we were able to identify a novel cluster of lipases with comparatively low homology to known lipases. The representative of this cluster shows a broad substrate range, high activity at moderate to low temperatures and halophilic properties.

\section{MATERIALS AND METHODS}

\section{Annotation of Predicted Proteins with Known Domains}

To identify predicted proteins with known domains, all GOS sequences were analyzed for domains from PfamA, PfamB, and TIGRFAM using the hmmsearch utility from HMMER 3.0 with an inclusion threshold $E$-value of $10^{-3}$ and a reporting threshold of $10^{-5}$. Domain Hidden Markov Models (HMMs) were obtained from ftp://ftp.ebi.ac.uk/pub/databases/Pfam/ and $\mathrm{ftp}$ ://ttp.jcvi.org/pub/data/TIGRFAMs/ (Pfam 27, TIGRFAM 14; Haft et al., 2003; Finn et al., 2014).

\section{Identification of Protein Families de novo}

The remaining 1.7 million sequences lacking known domains identifiable via HMMs were grouped using cd-hit hierarchical clustering in three steps $(90,75,60 \%$ similarity), sequences which could not be matched with other sequences in this way were discarded. To minimize redundancy, only sequences which resulted from cd-hit clustering by $90 \%$ similarity were used. Similarity distances between these sequences were determined by all-vs.-all protein BLAST. On the basis of all similarity distances the sequences were clustered with MCL at $i=1.4$ according to van Dongen and Abreu-Goodger (2011).

\section{Determination of Cluster Representatives}

For each de novo family, guide trees generated by MAFFT FFT-NS-2 Strategy were used to estimate the similarity distance 
between individual family members (Katoh et al., 2002). The sequence with the smallest total distance to all other sequences was chosen as the representative for a family.

\section{Search for Lipolytic Enzymes}

A regular expression pattern search for the active site of lipases and esterases was performed on all representatives from families lacking HMM annotation which consisted of more than 10 sequences. The regular expression sequences for the three lipase superfamilies were derived from the annotated multiple alignment of the Lipases Engineering Database (Pleiss et al., 2000; Widmann et al., 2010) and are stated in Table $\mathbf{1 .}$

The regular expression patterns define a necessary requirement for lypolytic activity but on its own are not sufficient. These sequences can, and do, randomly occur in unrelated proteins. We thus applied the set of HMMs of all families listed in the Lipase Engineering Database to the matching sequences to select for proteins that contain the pattern in the context of a typical hydrolase fold. The protein gi135157357 was the only candidate that matched these patterns with an $E$-value $\leq 10^{-5}$. This potential lipase from the GOS dataset (PL-GOS) was selected and the corresponding gene synthesized (GeneArt, Regensburg, Germany). The 3D-structure of PL-GOS was predicted using Phyre2 (Kelley et al., 2015). To determine, if the MCL clustering-based family of PL-GOS is indeed phylogenetically distinct from known lipases, a phylogenic NJ-tree tree (Kuraku et al., 2013) was created based on a MAFFT alignment of the PL-GOS family members with members of protein family abH 15.03 (sequences obtained from the Lipase Engineering Database) and abH 15.02 as outgroup. MAFFT strategy G-INS-I was used. The tree was visualized using Dendroscope 3 in a radial phylogram. abH 15.02 is not shown and was used to define the root.

\section{Protein Expression and Purification}

The PL-GOS gene was cloned into a pTAC-MAT-Tag-2 (SigmaAldrich, St. Louis, MO, USA) based vector with an ompA signaling sequence for periplasmic expression and a pET11a (Merck Millipore, Billerica, MA, USA) derivative for overexpression and purification via his-tag (see Table 2). The vectors were transformed into Escherichia coli strains MG1655 (periplasmic expression) and BL21 (DE3) (overexpression), respectively, by means of heat-shock transformation creating the strains listed in Table 2. All E. coli strains were grown in LBmedium (Bertani, 1951; without glucose), supplemented with $100 \mathrm{mg} \mathrm{L}^{-1}$ ampicillin at $37^{\circ} \mathrm{C}$. Expression of protein in strain

TABLE 1 | Regular expression patterns for the identification of carboxylester hydrolases used in this study.

\begin{tabular}{|c|c|}
\hline Superfamily & Regular expression pattern \\
\hline GX & $\begin{array}{l}\text { "/G[EFGHILMNRSTVWY].\{10,\}[AG].(S[AFHKLMQTVWY]| } \\
\text { C[FLWY])G. }\{10,\}[D E] .\{10,\} H / "\end{array}$ \\
\hline GGGX & $\begin{array}{l}\text { "/GG([AELNRSW]] } \\
\mathrm{G}[\mathrm{FL}]) .\{10,\}[A G] . S[A C F G I M S V Y] G .\{10,\}[D E] .\{10,\} \mathrm{H} / "\end{array}$ \\
\hline$Y$ & "Y.\{10,\}[AG].S[ANQWY]G.\{10,\}[DE].\{10,\}H/" \\
\hline
\end{tabular}

TABLE 2 | Strains of Escherichia coli used in this study.

\begin{tabular}{|c|c|c|}
\hline E. coli strain & Genotype & Source \\
\hline MG1655 & $\mathrm{F}^{-} \lambda^{-} i l v G^{-} r f b-50 \mathrm{rph}-1$ & $\begin{array}{l}\text { ATCC strain } \\
\text { 700926, American } \\
\text { Type Culture } \\
\text { Collection }\end{array}$ \\
\hline BL21 (DE3) & $\begin{array}{l}\mathrm{F}^{-} \mathrm{ompT}^{-} \mathrm{gal}^{-} \mathrm{dcm}^{-} \mathrm{lon}^{-} \text {hsdSB } \\
\left(\mathrm{r}_{\mathrm{B}}^{-} \mathrm{m}_{\mathrm{B}}^{-}\right) \lambda(\mathrm{DE} 3(\mathrm{lacl} \text { lacUV5-T7 } \\
\text { gene } 1 \text { ind1 sam7 nin5)) }\end{array}$ & $\begin{array}{l}\text { Stratagene, Santa } \\
\text { Clara, CA, USA }\end{array}$ \\
\hline TMMGP & $\begin{array}{l}\text { MG1655 pPC (pTAC-MAT-Tag-2 } \\
\text { with N-terminal OmpAss) }\end{array}$ & This work \\
\hline TMMGPK & $\begin{array}{l}\text { MG1655 pTM1 (Bacillus subtilis } \\
\text { lipA in pPC) }\end{array}$ & This work \\
\hline TMMGP1503 & MG1655 pTM2 (pl-gos in pPC) & This work \\
\hline TMBL1503 & $\begin{array}{l}\text { BL21 (DE3) pTM3 (pl-gos with } \\
\text { N-terminal His6-Tag and TEV } \\
\text { cleavage site in pEt-11a) }\end{array}$ & This work \\
\hline
\end{tabular}

TMMGPK and TMMGP1503 was induced by addition of $1 \mathrm{mM}$ IPTG to the medium $2 \mathrm{~h}$ prior to cell disruption for qualitative para-nitrophenyl ester ( $\mathrm{pNP}$ ) assays with crude cell extract and in TMBL1503 $4 \mathrm{~h}$ prior to cell disruption for protein purification at an $\mathrm{OD}_{600}$ of 0.5 .

Cells for crude extract for pNP-ester assays were harvested for $30 \mathrm{~s}$ at $13,000 \times \mathrm{g}$. The pellet was resuspended in $50 \mathrm{mM}$ tris-HCl-buffer, $\mathrm{pH}$ 7.3. Crude extract was obtained by cell disruption using a Vial Tweeter (Hielscher, Teltow, Germany) at $80 \%$ amplitude in $0.5 \mathrm{~s}$ intervals for $3 \times 1 \mathrm{~min}$ and subsequent spinning down of the insoluble cell debris for $20 \mathrm{~min}$ at $13,000 \times$ $g$ and $4^{\circ} \mathrm{C}$.

For the purification of PL-GOS cells were harvested by centrifugation for $30 \mathrm{~min}$ at $4^{\circ} \mathrm{C}$ and $7,800 \times \mathrm{g}$. The pellet was resuspended in $100 \mathrm{ml} 50 \mathrm{mM}$ tris-HCl-buffer, $\mathrm{pH} 7.3$ per $10 \mathrm{~g}$ wet weight including Complete EDTA-free Protease Inhibitor Cocktail (Roche, Mannheim, Germany) (one tablet per $80 \mathrm{ml}$ solution). Next, cells were disrupted three times using a Constant Cell Disruption System (Constant Systems, Low March, UK) at $1.9 \mathrm{kbar}$. The lysate was again supplemented with one tablet of Complete EDTA-free Protease Inhibitor Cocktail per $80 \mathrm{ml}$ solution and $1 \mathrm{mM}$ PMSF. The cell lysate was subsequently separated from cell debris for $1 \mathrm{~h}$ at $4^{\circ} \mathrm{C}$ and $7,800 \times g$ by centrifugation. Supernatant was filtered using $250 \mathrm{ml}$ Filtropur V50 vacuum filters (Sarstedt, Nümbrecht, Germany). Purification and fractionation steps were performed with an ÄKTApurifier (GE Healthcare, Uppsala, Sweden). Filtrate was loaded onto a $5 \mathrm{ml}$ HisTrap HP Ni-NTA-column (GE Healthcare, Uppsala, Sweden) equilibrated with buffer A (50 mM sodium phosphate, $300 \mathrm{mM} \mathrm{NaCl}, \mathrm{pH} 8.0$ ). Elution was performed using $150 \mathrm{ml}$ of a gradient from $98 \%$ buffer A and $2 \%$ buffer B (=buffer A containing $500 \mathrm{mM}$ imidazole) to $100 \%$ buffer $\mathrm{B}$ at a flow rate of $1.67 \mathrm{ml} \mathrm{min}^{-1} .3 \mathrm{ml}$ fractions were collected and analyzed by SDS-PAGE. Fractions with the highest protein yield were unified and his $_{6}$-tagged TEV protease was added to the target protein at a 30-fold excess. The protein solution was dialyzed against $50 \mathrm{mM}$ HEPES-buffer in a Spektra/Por Dialysis Membrane 12$14 \mathrm{kDa}$ (Spectrumlabs, Rancho Dominguez, USA) at $4^{\circ} \mathrm{C}$. Next the protein solution was again loaded onto a Ni-NTA-column and 
eluted with buffer A to remove the his 6 -tagged TEV protease and the residual his 6 tag. The flow-through was once again dialyzed against $50 \mathrm{mM}$ HEPES-buffer and concentrated using $10 \mathrm{kDa}$ filter concentrators (Santorius Stedim, Göttingen, Germany). A purity of $>95 \%$ was achieved as assessed by SDS-PAGE.

\section{Lipolytic Activity Assays}

Hydrolytic activity toward triglycerides was tested using LB agar plates containing $100 \mathrm{mg} \mathrm{L}^{-1}$ ampicillin, $100 \mu \mathrm{M}$ IPTG and either $1 \%(\mathrm{w} / \mathrm{v})$ tributyrin or $1 \%(\mathrm{w} / \mathrm{v})$ triolein and $0.001 \%(\mathrm{w} / \mathrm{v})$ Rhodamin B (Sigma-Aldrich, St. Louis, MO, USA). MG1655 colonies were incubated for 2 days at $37^{\circ} \mathrm{C}$. Hydrolytic activity was indicated by clear halos around the colonies for tributyrin and under UV light orange fluorescent halos for triolein.

Lipolytic activity was tested by using pNP-esters (pNPbutyrate, C4; pNP-octanoate, C8; pNP-decanoate, C10; pNPduodecanoate, C12; pNP-myristate, C14, and pNP-palmitate, C16) (Sigma-Aldrich, St. Louis, MO, USA) as substrates. A reaction sample containing $65 \mathrm{nM}$ purified PL-GOS or $1 \%$ (v/v) crude extract in $50 \mathrm{mM}$ tris-HCl-buffer, $\mathrm{pH} 7.3$ was kept at a constant temperature. The reaction was started by adding $200 \mu \mathrm{M}$ pNP-ester from a $4 \mathrm{mM}$ stock in aqueous solution with $4 \%$ ethanol, $1 \%$ acetonitrile, and $0.4 \%$ Triton-X100 and was observed by measuring the $\mathrm{OD}_{405}$ of the sample over the course of $10 \mathrm{~min}$. To analyze the temperature optimum pNP-butyrate was used as a substrate and reactions were repeated at different temperatures ranging from 10 to $45^{\circ} \mathrm{C}$. The salt concentration optimum was detected by replacing tris-HCl-buffer, $\mathrm{pH} 7.3$ with artificial seawater $\left(28.13 \mathrm{~g} / \mathrm{l} \mathrm{NaCl} ; 3.5 \mathrm{~g} / \mathrm{l} \mathrm{MgSO}_{4} \cdot 7 \mathrm{H}_{2} \mathrm{O} ; 2.55 \mathrm{~g} / \mathrm{l}\right.$ $\mathrm{MgCl}_{2} ; 1.2 \mathrm{~g} / \mathrm{l} \mathrm{CaCl}$; $0.77 \mathrm{~g} / 1 \mathrm{KCl} ; 0.11 \mathrm{~g} / 1 \mathrm{NaHCO}_{3}$ ) (Atlas, 2010) using pNP-butyrate as the substrate at a temperature of $20^{\circ} \mathrm{C}$. Different osmolarities were established by adding or withholding
$\mathrm{NaCl}$. For measurement of the Michaelis Menten kinetics, the reaction was performed in tris-HCl-buffer, $\mathrm{pH} 7.3$ with different substrate concentrations of pNP-butyrate and pNP-palmitate ranging from 5 to $333 \mu \mathrm{M}$.

For activity assays with crude extract the TMMGPK strain expressing lipase A from B. subtilis was used as positive control, the TMMGP strain containing an empty vector was used as a negative control.

\section{Detection of Enantioselectivity}

Racemic $(R, S)-\alpha$ - $\left(4^{\prime}\right.$-isobutylphenyl)-propionic acid methyl ester $(R, S)$ and $(R, S)$ - $\alpha$-phenylpropionic acid ethyl ester $(R, S)$ were prepared from the commercially available corresponding racemic acid by acid-catalyzed esterification with methanol and ethanol, respectively. The structure of the products was confirmed by ${ }^{1} \mathrm{H}-\mathrm{NMR}$. For the biocatalysis reaction, racemic ester (11 $\mathrm{mM})$ was dissolved in Tris-HCl buffer (50 mM, pH 7) with DMSO (10\% v/v) as cosolvent. Purified PL-GOS $(0.18 \mathrm{mg})$ was added to a total volume of $1 \mathrm{~mL}$ and the reaction mixture was incubated in a thermoshaker at $37^{\circ} \mathrm{C}$ and $900 \mathrm{rpm}$. The reaction was monitored by thin layer chromatography and was stopped after $120 \mathrm{~h}$, at approximately $50 \%$ conversion. The reaction mixture was extracted twice with methyl tert butyl ether (MTBE, $0.4 \mathrm{~mL}$ ). The organic solvent was dried over magnesium sulfate and removed under dry air. Substrate and product of the methyl ester hydrolysis were separated by TLC and the produced acid dissolved in MTBE. The acid products of both hydrolysis reactions were converted into the corresponding methyl esters with TMS-diazomethane (Sigma-Aldrich) according to the instructions of the manufacturer. The optical purity of the reactants was determined using a chiral gas
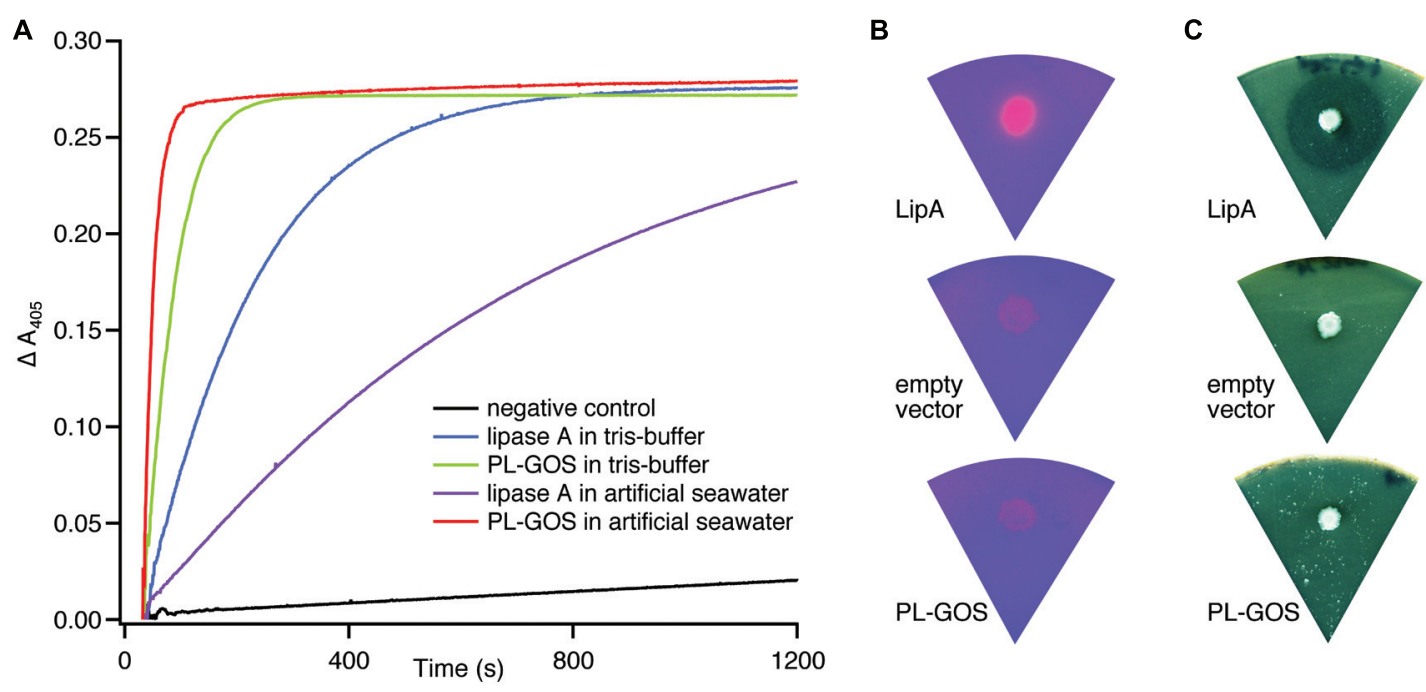

FIGURE 1 | Esterase activity of PL_GOS. (A) Hydrolysis of pNP-butyrate by PL-GOS. Crude extract from Escherichia coli MG1655 cells expressing PL-GOS (strain TMMGP1503) and lipase A (strain TMMGPK) from Bacillus subtilis was used. Crude extract from E. coli TMMGP (empty vector) served as negative control. Activity of crude extracts was tested in tris-HCl-buffer, $\mathrm{pH} 7.3$ and artificial seawater. PL-GOS activity increased in artificial seawater, while lipase A activity decreased. Plate based lipolytic assays with triolein/rhodamin (B) and tributyrate as substrate (C) show no lipase activity in E. coli TMMGP1503 expressing PL-GOS from a plasmid. E. coli TMMGPK expressing Lipase A from B. subtilis was used as a positive control and E. coli TMMGP with an empty vector was used as negative control. 

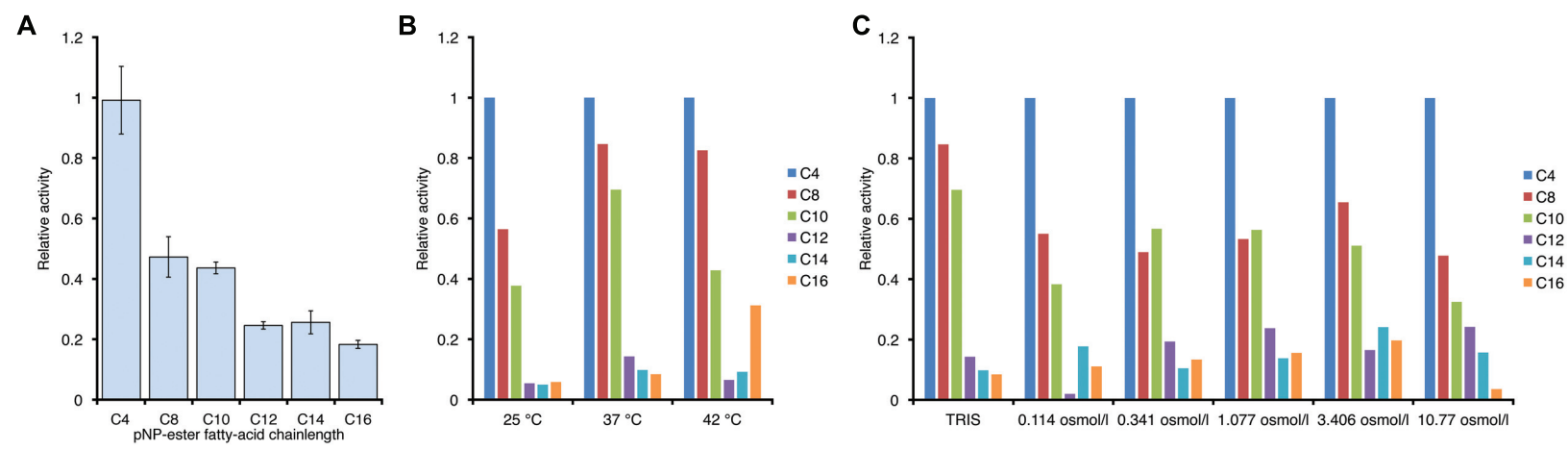

FIGURE 2 | Chain length specificity of the hydrolase activity of PL-GOS. (A) pNP esters with different acid residue chain length where tested at $20^{\circ} \mathrm{C}$ in tris-HCl-Buffer, $\mathrm{pH}$ 7.3. Enzyme concentration was at $65 \mathrm{nM}$, substrate concentration was $200 \mu \mathrm{M}$. Activity is expressed relative to activity toward pNP-butyrate. Relative preference for shorter chain length did not change with temperature, as tested in tris- $\mathrm{HCl}$-Buffer (B) or osmolarity of the buffer, as tested at $37^{\circ} \mathrm{C}(\mathbf{C})$. Experiments for (B) and (C) were conducted once.

TABLE 3 | Enzymatic properties of PL-GOS.

\begin{tabular}{lcc}
\hline Property & pNP-butyrate & pNP-palmitate \\
\hline (apparent) $\mathrm{K}_{\mathrm{m}}(\mu \mathrm{M})$ & 66.68 & 68.08 \\
$\mathrm{~V}_{\max }(\mu \mathrm{M} / \mathrm{min})$ & 400 & 50.76 \\
$\mathrm{~K}_{\text {cat }}\left(\mathrm{S}^{-1}\right)$ & 228 & 45 \\
$\mathrm{~K}_{\text {cat }} / \mathrm{K}_{\mathrm{m}}\left(\mathrm{M}^{-1} \mathrm{~S}^{-1}\right)$ & $3.4^{*} 10^{6}$ & $6.6 * 10^{5}$ \\
\cline { 2 - 3 } & \multicolumn{3}{c}{$19.85^{\circ} \mathrm{C}$} \\
Temperature optimum & \multicolumn{3}{c}{$3.89 \mathrm{osmol} / \mathrm{l}$} \\
\hline
\end{tabular}

chromatography column (Macherey-Nagel Hydrodex-ß6TBDM, $25 \mathrm{~m} \times 0,25 \mathrm{~mm}$ ) in a Shimadzu GC-2010 gas chromatograph using hydrogen as carrier gas. Using $125^{\circ} \mathrm{C}$ column temperature, $\alpha$-( $4^{\prime}$-isobutylphenyl)-propionic acid methyl ester eluted at $14.50 \mathrm{~min}(S)$ and $14.80 \mathrm{~min}(R)$. Using $85^{\circ} \mathrm{C}$ column temperature, $\alpha$-phenylpropionic acid methyl ester eluted at $15.80 \mathrm{~min}(S)$ and $16.30 \mathrm{~min}(R)$. The $E$-value of the biocatalysis of $\alpha$-phenylpropionic acid ethyl ester were calculated using conversion according to gas chromatography and eeP. E-value and conversion of the biocatalysis of $\alpha-\left(4^{\prime}-\right.$ isobutylphenyl)-propionic acid methyl ester were calculated using eeS and eeP according to the equation from Chen et al. (1982).

\section{RESULTS}

\section{Bioinformatic Search for Lipolytic Enzymes}

The GOS project is the biggest metagenomic project to date. It contains genomic data from planktonic microorganisms collected in oceanic surface water around the globe (Rusch et al., 2007). The $6,123,395$ sequences of potential proteins from the GOS project were searched for potential novel lipolytic enzymes. In a first step, we bioinformatically assigned protein functions to these sequences using PfamA, PfamB, and TIGRFAM HMMs. Proteins that matched with an $E$-value below $10^{-5}$ were considered as "annotated". These annotated sequences were removed from the protein sequence pool. The remaining 1.7 million sequences, which we considered of "unknown" function, were clustered at $90 \%$ similarity to avoid redundancy in the sequences. The resulting 706,208 sequences were then clustered using the markov-clustering algorithm MCL (van Dongen and Abreu-Goodger, 2011). This resulted in 17,795 clusters consisting of more than 10 sequences. We then identified one representative protein for each of these clusters. To do so, the protein with the minimal phylogenetic distance to all other proteins in the cluster was chosen. We argued that this protein best represents all other members of the cluster. We then pre-screened these representatives with a naive motif-search for the consensus active site sequences of the three lipase superfamilies GX, GGGX, and $\mathrm{Y}$ (Table 1). This resulted in 470 sequences matching the search criteria for class GX, 149 sequences matching the search criteria for class GGGX and 158 sequences matching the search criteria for class Y. While the active site sequences are necessary but not sufficient for a lipase, we also used a HMM search for the hallmark alpha/beta hydrolase fold. This search was performed using HMMs describing the families of the Lipase Engineering Database (Pleiss et al., 2000). The protein gi135157357 (PL-GOS) from the GX-superfamily was the only sequence that matched with a significant $E$-value. The known lipase family closest to PL-GOS was abH15.03 (Saccharomyces cerevisiae lipase 2 like). A BLASTP comparison of PL-GOS and Saccharomyces cerevisiae lipase 2 showed an identity of 25, and $42 \%$ positive amino acid matches. The closest matches in the NCBI non-redundant sequence database using BLASTP were uncharacterized, hypothetical proteins of Balneola vulgaris and Gracilimonas tropica with an identity of $49 \%$ each and $69 \%$ and $68 \%$ positive amino acid matches, respectively. This potential lipase was then synthesized and cloned into our vector systems for periplasmic expression and overexpression.

\section{PL-GOS is a Lipase}

To test this metagenomic protein for lipase or esterase activity, we tested activity in crude extract of E. coli MG1655 cells expressing 

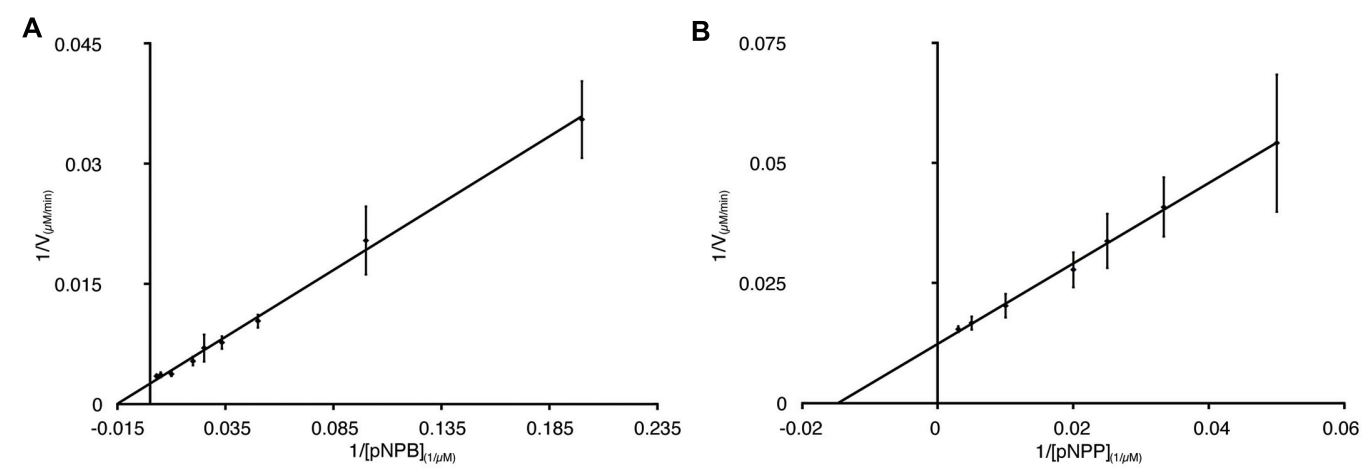

FIGURE 3 | Enzymatic parameters of PL-GOS. $K_{m}$ and $V_{\max }$ toward pNP-butyrate (A) and pNP-palmitate (B) were derived from Lineweaver-Burk plots with a linear fit. The $\mathrm{x}$-axis displays 1/[substrate] in $\mu \mathrm{M}^{-1}$. For pNP-butyrate the $\mathrm{K}_{\mathrm{m}}$ was $66.68 \mu \mathrm{M}$ and $\mathrm{V}_{\max }$ was $400 \mu \mathrm{M} / \mathrm{min}$. The apparent $\mathrm{K}_{\mathrm{m}}$ of pNP-palmitate was $24.18 \mu \mathrm{M}$ with a $V_{\max }$ of $50.76 \mu \mathrm{M} / \mathrm{min}$. Enzyme concentration was $65 \mathrm{nM}$, assays were performed at $20^{\circ} \mathrm{C}$.
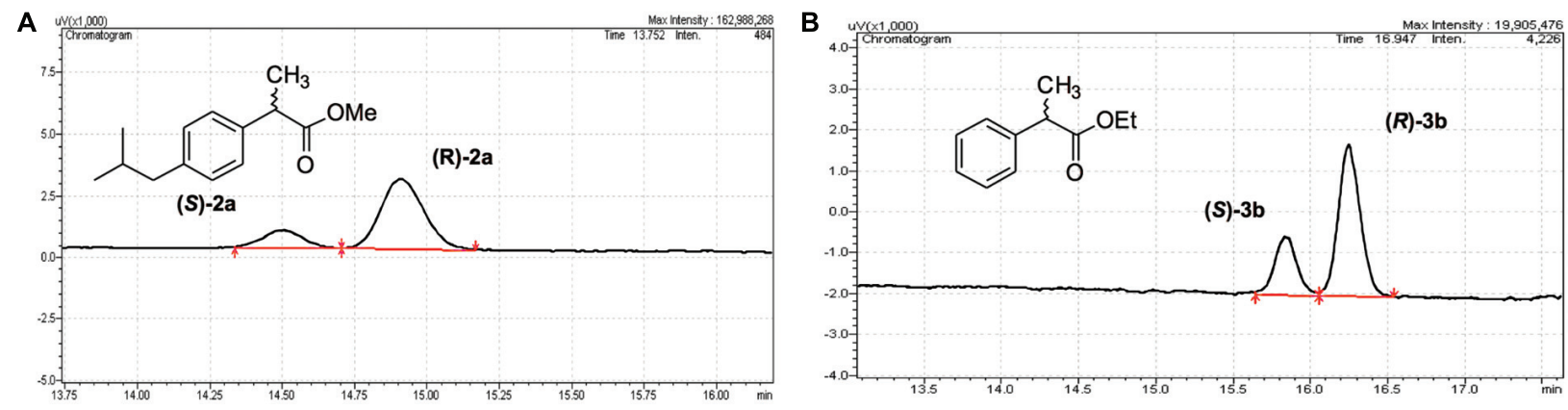

FIGURE 4 | Enantioselectivity of PL-GOS. PL-GOS preferably hydrolyzes the R-enantiomers of Ibuprofen methyl ester (A) and phenylpropionic acid methyl ester (B). Racemic mixtures of the respective esters were incubated with PL-GOS, then products were derivatized with TMS-diazomethane and separated on a chiral gas chromatography column.

PL-GOS from a plasmid. PL-GOS crude extract showed activity against pNP-butyrate similar to crude extract of MG1655 cells expressing B. subtilis lipase A, which we used as a positive control (Figure 1A). The activity of PL-GOS could be increased by exchanging the tris-HCl-buffer, $\mathrm{pH} 7.3$ in the reaction solution for artificial seawater. This also resulted in lower activity of the positive control and suggested to us that PL-GOS could have halotolerant properties.

From the general potential of PL-GOS to hydrolyze organic ester bonds in substrates with long fatty acid chains like pNPpalmitate, we concluded that PL-GOS is a lipase, though direct hydrolytic activity toward triglycerides could not be shown in our assays (Figures 1B,C).

\section{PL-GOS has a Broad Range of Substrate Chain Length}

We therefore decided to determine the biochemical characteristics of this biocatalyst in more detail. By attaching an N-terminal $\mathrm{His}_{6}$-tag we were able to purify PL-GOS to $95 \%$ homogeneity. Esterases typically prefer hydrophilic substrates and thus generally show a lower activity toward substrates with longer carbon chains. Some esterases do not show any activity toward pNP esters with a chain length longer than $\mathrm{C}_{8}$
(Yu et al., 2010), while others have a maximum activity toward pNP- $\mathrm{C}_{8}$ and lower activity toward shorter and longer chained pNP-esters (Choi et al., 2004). The chain length specificity of PL-GOS for the hydrolysis of pNP-esters was determined by using $\mathrm{pNP}$-esters with variable acid residue lengths ranging from butyrate (C4) to palmitate (C16). PL-GOS exhibited its highest activity toward pNP-butyrate. It showed a decrease of activity with increasing length of the acid residue chain. The activity toward pNP-octanoate (C8) was $47.6 \%$, the activity toward pNP-palmitate (C16) $13.3 \%$ of the activity toward the preferred pNP-butyrate (C4) substrate (Figure 2). This indicates that while PL-GOS prefers shorter chains, it hydrolyzes a broad spectrum of substrate chain lengths, which is typical for some lipases.

\section{Enzyme Kinetics of PL-GOS}

To further characterize the activity of PL-GOS, its Michaelis Menten kinetics toward pNP-butyrate and pNP-palmitate were determined (Table 3). The $\mathrm{K}_{\mathrm{M}}$ of PL-GOS toward pNP-butyrate was $66.68 \mu \mathrm{M}$. From our experiments we derived a $k_{\text {cat }}$ value of $228 \mathrm{~s}^{-1}$ and a $k_{\text {cat }} / K_{\mathrm{M}}$ value of $3.4 * 10^{6} \mathrm{M}^{-1} \mathrm{~s}^{-1}$ (Figure 3A). Compared to esterases which are specialized to hydrolize esterbonds with short-chain fatty acids, PL-GOS shows a very high affinity for its preferred substrate, but a comparatively low $\mathrm{V}_{\max }$ 
A

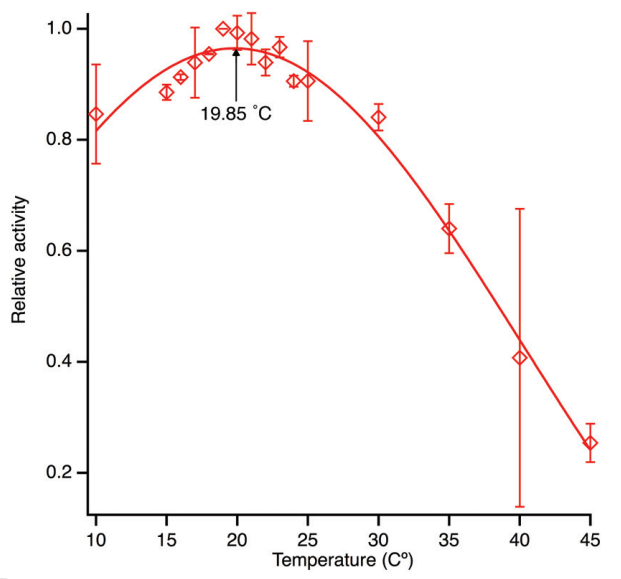

B

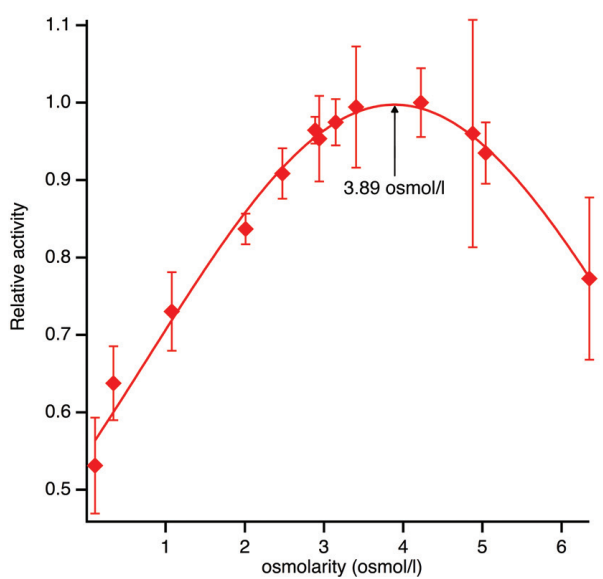

C

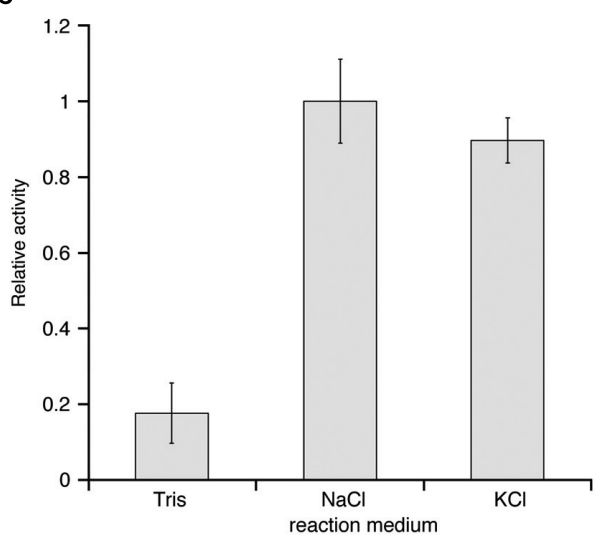

FIGURE 5 | Temperature and osmolarity optimum of PL-GOS using pNP-butyrate as substrate. (A) Activity was measured at different temperatures between 10 and $45^{\circ} \mathrm{C}$ in tris- $\mathrm{HCl}$-buffer, $\mathrm{pH} 7.3$ and set in relation to the highest activity. An optimum temperature of $19.85^{\circ} \mathrm{C}$ was calculated by gaussian curve fitting. (B) Activity of PL-GOS at $19.85^{\circ} \mathrm{C}$ in solutions with different osmolarities made by adjusting $\mathrm{NaCl}$ concentrations in artificial seawater and set in relation to the highest activity. An optimum of $3.89 \mathrm{osmol} / \mathrm{l}$ was calculated using gaussian curve fitting. (C) Influence of alkali metal cations on the activity of PL-GOS: Artificial seawater with three times higher osmolarity than standard was prepared by the addition of either $\mathrm{NaCl}$ or $\mathrm{KCl}$. No significant difference between the cationic composition of the buffer was found. Activity in Tris- $\mathrm{HCl}$ for comparison.
(Choi et al., 2004; Lee et al., 2006; Yu et al., 2010). Toward pNP-palmitate, the apparent $\mathrm{K}_{\mathrm{M}}$ of PL-GOS was measured to be similar with $68.08 \mu \mathrm{M}$ at substrate concentrations above $20 \mu \mathrm{M}$. At lower concentrations of pNP-palmitate PL-GOS displayed non-Michaelis Menten kinetics and the apparent $\mathrm{K}_{\mathrm{M}}$ was lower. This might be due to the propensity of the substrate to form micelles (see Discussion, Figures 6 and 7). The $k_{\text {cat }}$ value at substrate concentrations above $20 \mu \mathrm{M}$, on the other hand was significantly lower at $45 \mathrm{~s}^{-1}$, when compared to pNP-butyrate, resulting in a $k_{\text {cat }} / K_{\mathrm{M}}$ value of $6.6^{*} 10^{5} \mathrm{M}^{-1} \mathrm{~s}^{-1}$ (Figure 3B). The high activity toward long-chain fatty acids suggests that PL-GOS is a lipase. Some other lipases show a significantly lower affinity toward pNP-palmitate when compared to PL-GOS. The lipase of Burkholderia cepia, for example, has a $\mathrm{K}_{\mathrm{M}}$ toward pNP-palmitate of $12 \mathrm{mM}$ (Sharma et al., 2001).

\section{PL-GOS Shows Moderate Enantioselectivity}

The lipase-catalyzed kinetic resolution of racemic chiral esters is a widely used route for the synthesis of optically pure compounds. To investigate a potential application of PL-GOS, we studied the kinetic resolution of two racemic esters. Ibuprofen is a non-steroidal inflammatory drug and is one of the most-sold over-the-counter drugs (Kourist et al., 2011). Biocatalysis offers an environmentally friendly approach for the preparation of these compounds in optically pure form. Phenylpropionic acid is a chiral building block for pharmaceutical synthesis and is a model compound for the conversion of profens. PL-GOS showed promising enantioselectivity in the kinetic resolution of esters of these compounds. It shows preference toward the $(R)$-enantiomers and enantioselectivity of $E=3-4$, which allows synthesis of the products in enantioenriched form $(43 \%$ ee for Ibuprofen methyl ester and 61\%ee for the ethyl ester of phenylpropionic acid; Figure 4). This moderate selectivity suggests a potential of PL-GOS as enantioselective biocatalyst.

\section{PL-GOS is a Phsychrophilic and Halotolerant Enzyme}

Due to its maritime origin we speculated that PL-GOS would be most active at mild to cold temperatures. The activity of PLGOS was therefore measured at different temperatures in the range between $10^{\circ} \mathrm{C}$ and $45^{\circ} \mathrm{C}$. From this data the temperature optimum could be interpolated to be $19.85^{\circ} \mathrm{C}$ (Figure 5A; Table 3), while still retaining $80 \%$ of its activity at $10^{\circ} \mathrm{C}$. At higher temperatures its activity diminished and at $45^{\circ} \mathrm{C}$ it showed only a quarter of its maximum activity.

Another characteristic, which we speculated PL-GOS could possess due to its maritime origins, was a tolerance or affinity for high salt concentrations. In our crude extract assays we already determined that PL-GOS has a higher activity in artificial seawater when compared to tris-HCl-buffer, $\mathrm{pH}$ 7.3. The osmolarity optimum was therefore determined next. To do this, different reaction buffers with varying $\mathrm{NaCl}$ concentrations, derived from artificial seawater, were used in a pNP-butyrate hydrolysis assay. This revealed an osmolarity optimum of 3.89 osmol L $\mathrm{L}^{-1}$, which amounts to 3.61 -fold the osmolarity 
A

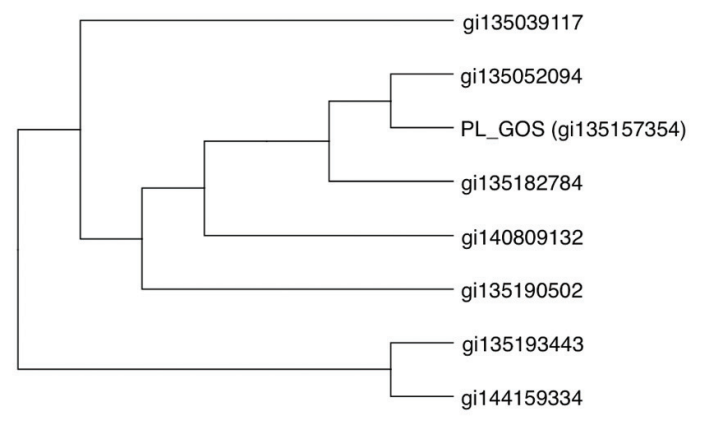

B

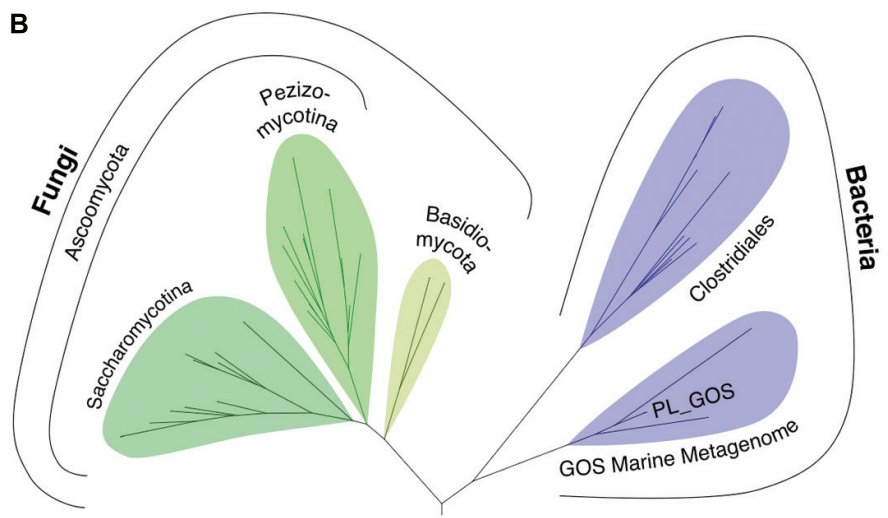

FIGURE 6 | Phylogenetic analysis of the metagenomic sequences of the cluster of potential lipases containing PL-GOS. (A) Unrooted phylogenetic tree of all eight complete, non-redundant sequences of the PL-GOS cluster. (B) Phylogenetic tree of lipase sequences from family abH 15.03 from the Lipase Engineering Database and the PL-GOS cluster. The PL-GOS cluster forms a discrete subfamily in the bacterial branch of abH 15.03 . Sequences from family abH 15.02 were used as an outgroup to define the root.

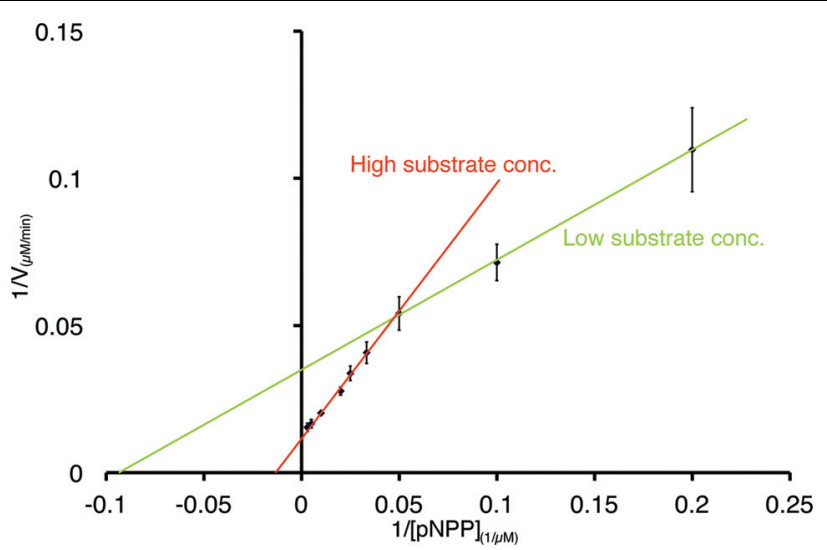

FIGURE 7 | Non-Michaels Menten kinetics of PL-GOS at low substrate concentrations of pNP-palmitate. Lineweaver-Burk plot of PL-GOS enzyme kinetics with pNP-palmitate as substrate. At low concentrations $(\leq 20 \mu \mathrm{M})$, the apparent $\mathrm{K}_{\mathrm{m}}$ of PL-GOS was $10.64 \mu \mathrm{M}$, at higher concentrations the $\mathrm{K}_{\mathrm{m}}$ was higher at $68.08 \mu \mathrm{M}$.

of artificial seawater (Figure 5B; Table 3). Dependency of the increased activity on $\mathrm{Na}^{+}$-ions was tested by interchanging $\mathrm{NaCl}$ with $\mathrm{KCl}$. No significant difference between reaction medium with a high concentration of $\mathrm{NaCl}$ or a high concentration of $\mathrm{KCl}$ could be detected (Figure 5C).

\section{DISCUSSION}

We present here a combined bioinformatics/biochemistry approach for the discovery of new biocatalytic enzymes from metagenomic datasets. The amount of proteins encoded in the DNA of microbial communities is enormous. In a typical metagenomic discovery project it is therefore necessary to create large expression libraries with $100 \mathrm{~s}$ of 1000 s of clones and screen this library for a specific enzyme activity. These projects have generated many new biocatalysts (Coughlan et al., 2015). However, this process is resource- and time-consuming and often yields only a low hit per clone ratio typically in the range of $10^{-6}$ to $10^{-4}$ depending on the size of the DNA fragments used (Lämmle et al., 2007). This low ratio is not necessarily the result of a low frequency of the occurrence of proteins with the screened-for activity, but also based on the imperfect positioning of the genes in the expression library. With the advent of high-throughput "next-generation" sequencing, a bioinformatics approach can substitute the creation and screening of an expression library. This approach allows for a first "screening" in silico. Once established, the bioinformatical screening process can be applied to further metagenomic datasets with little to no additional cost. However, highthroughput bioinformatics cannot yet annotate every potential protein correctly (Godzik, 2011). Thus, one disadvantage of a discovery strategy solely based on a bioinformatic homology search is the dismissal of protein families with a low homology to known biocatalysts. Here we present an approach to find a biocatalyst through systematic application of different bioinformatics search methods to a metagenomic dataset.

We identify the novel lipase PL-GOS, representative member of a cluster of 27 potential lipase sequences in the GOS dataset. The genes with an unambiguously predicted start and stop codon in this cluster encode eight complete proteins (Figure 6A), the rest encodes partial protein sequences. A phylogenetic analysis revealed that this cluster forms a discrete bacterial subfamily of the abH15.03 (Saccharomyces cerevisiae lipase 2 like) family from the Lipase Engineering Database (Figure 6B). PLGOS a phsychrophilic and halophilic lipase. Especially toward substrates with long carboxylic acid chains PL-GOS showed a favorable activity when compared to other carboxylester hydrolases (Sharma et al., 2001; Choi et al., 2004; Lee et al., 2006; Yu et al., 2010). Due to the propensity of pNP-palmitate to form micelles, the determination of kinetic parameters for this 
A

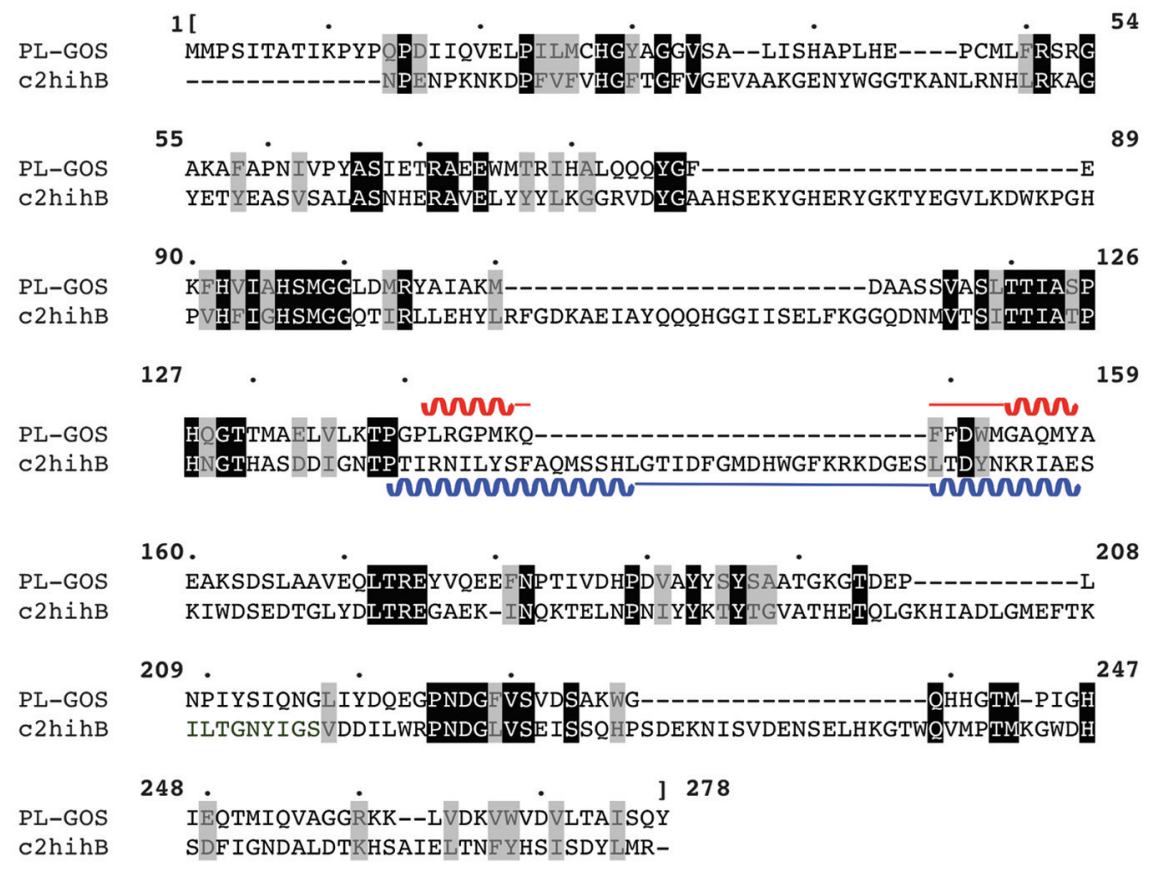

B

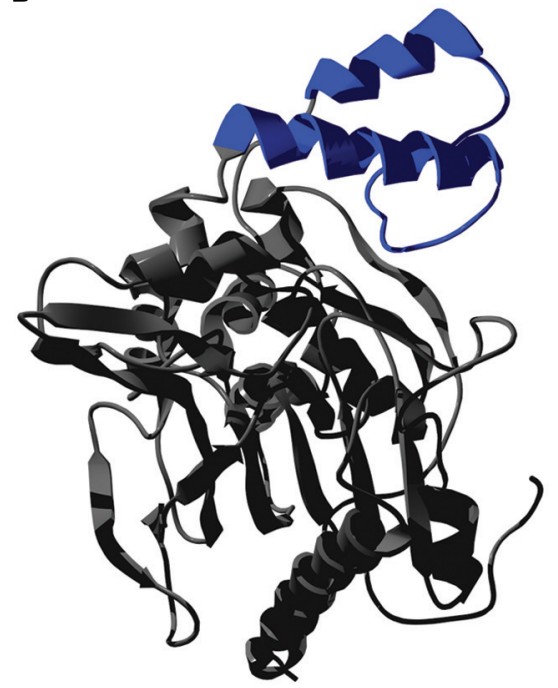

C

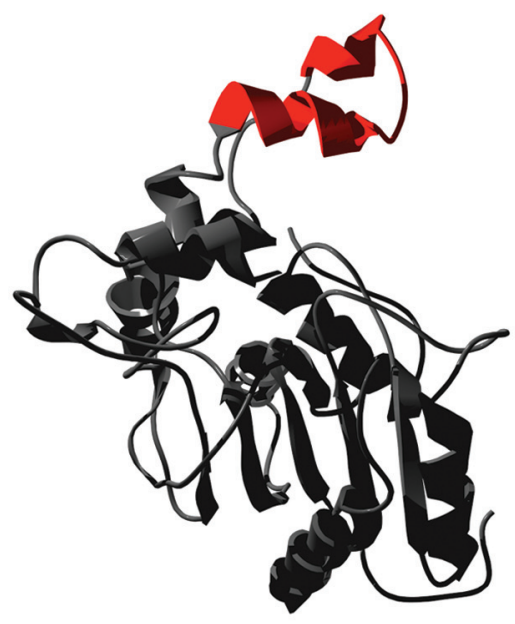

FIGURE 8 | Predicted lid structure of PL-GOS. PL-GOS was aligned with the lipase of Staphylococcus hyicus (c2hihB in the PDP database), a lipase with a known 3D-structure and 22\% identity with PL-GOS (A). The known structure of S. hyicus lipase (B) was used for 3D modeling of PL-GOS by Phyre2 (C). The lid structures are highlighted in blue and red, respectively. In case of PL-GOS the predicted lid structure is truncated.

substrate is challenging. Indeed, the apparent $\mathrm{K}_{\mathrm{M}}$ at very low concentrations of pNP-palmitate was measurably lower than with high and medium concentrations (Figure 7).

A Phyre2 alignment to predict the 3D structure of PL-GOS showed highest similarity to a Staphylococcus hyicus lipase, which is descriped to have a lid structure (Tiesinga et al., 2007). The predicted 3D-structure of PLGOS shows a truncated lid (Figure 8) which further points to PL-GOS being a lipase. However, although the Phyre2 confidence score for the structural model is high (at 100.0), its prediction is based on weak homology $(22 \%$ sequence identity), so its validity can be questioned. Furthermore, no activity toward triglycerides could be detected in our plate assays.

The commercial viability of biocatalysts depends on many factors and advances in protein engineering in recent years have shown great success in enhancing enzyme characteristics and specializing their uses for industrial application in biocatalysts 
as a whole (Bornscheuer et al., 2012; Li and Cirino, 2014) and carboxylesterases in particular (Widersten, 2014). The very mild temperature requirements and interesting osmolarity dependencies of PL-GOS in combination with its broad substrate range could form the basis of protein engineering enterprises.

\section{FUNDING}

Principal funding for this work was provided by the European Research Council under the European Union's Seventh Framework Programme (FP7/2007-2013)/ERC Grant agreement $\mathrm{n}^{\circ}$ 281384-FuMe to LIL and German Federal

\section{REFERENCES}

Amann, R. I., Ludwig, W., and Schleifer, K. H. (1995). Phylogenetic identification and in situ detection of individual microbial cells without cultivation. Microbiol. Rev. 59, 143-169.

Atlas, R. M. (2010). Handbook of Microbiological Media, 4th Edn. Boca Raton, FL: CRC Press.

BCC Research (2014). Global Markets for Enzymes in Industrial Applications. (Wellesley: BCC Research), 146.

Berlemont, R., Spee, O., Delsaute, M., Lara, Y., Schuldes, J., Simon, C., et al. (2013). Novel organic solvent-tolerant esterase isolated by metagenomics: insights into the lipase/esterase classification. Rev. Argent. Microbiol. 45, 3-12.

Bertani, G. (1951). Studies on lysogenesis. I. The mode of phage liberation by lysogenic Escherichia coli. J. Bacteriol. 62, 293-300.

Bornscheuer, U. T., Huisman, G. W., Kazlauskas, R. J., Lutz, S., Moore, J. C., and Robins, K. (2012). Engineering the third wave of biocatalysis. Nature 485, 185-194. doi: 10.1038/nature11117

Brady, L., Brzozowski, A. M., Derewenda, Z. S., Dodson, E., Dodson, G., Tolley, S., et al. (1990). A serine protease triad forms the catalytic centre of a triacylglycerol lipase. Nature 22, 767-770. doi: 10.1038/343767a0

Chen, C. S., Fujimoto, Y., Girdaukas, G., and Sih, C. J. (1982). Quantitative analyses of biochemical kinetic resolutions of enantiomers. J. Am. Chem. Soc. 104, 7294-7299. doi: 10.1021/ja00389a064

Choi, Y. J., Miguez, C. B., and Lee, B. H. (2004). Characterization and heterologous gene expression of a novel esterase from Lactobacillus casei CL96. Appl. Environ. Microbiol. 70, 3213-3221. doi: 10.1128/AEM.70.6.3213-3221.2004

Coughlan, L. M., Cotter, P. D., Hill, C., and Alvarez-Ordóñez, A. (2015). Biotechnological applications of functional metagenomics in the food and pharmaceutical industries. Front. Microbiol. 6:672. doi: 10.3389/fmicb. 2015.00672

Dartois, V., Baulard, A., Schanck, K., and Colson, C. (1992). Cloning, nucleotide sequence and expression in Escherichia coli of a lipase gene from Bacillus subtilis 168. Biochim. Biophys. Acta 1131, 253-260. doi: 10.1016/0167-4781(92)9 0023-S

Divakar, S., and Manohar, B. (2007). "Use of lipases in the industrial production of esters," in Industrial Enzymes, eds J. Polaina and A. P. MacCabe (Dordrecht: Springer), 283-300. doi: 10.1007/1-4020-5377-0-17

Finn, R. D., Bateman, A., Clements, J., Coggill, P., Eberhardt, R. Y., Eddy, S. R., et al. (2014). Pfam: the protein families database. Nucleic Acids Res. 42, D222-D230. doi: $10.1093 /$ nar/gkt1223

Godzik, A. (2011). Metagenomics and the protein universe. Curr. Opin. Struct. Biol. 21, 398-403. doi: 10.1016/j.sbi.2011.03.010

Gupta, R., Gupta, N., and Rathi, P. (2004). Bacterial lipases: an overview of production, purification and biochemical properties. Appl. Microbiol. Biotechnol. 64, 763-781. doi: 10.1007/s00253-004-1568-8

Haft, D. H., Selengut, J. D., and White, O. (2003). The TIGRFAMs database of protein families. Nucleic Acids Res. 31, 371-373. doi: 10.1093/nar/gkg128

Henne, A., Schmitz, R. A., Bömeke, M., Gottschalk, G., and Daniel, R. (2000). Screening of environmental DNA libraries for the presence of genes conferring
Ministry of Science and Education (Project-ID: 031A305B) to RK.

\section{ACKNOWLEDGMENTS}

TM and LL designed the experiments, TM, SN, AK, and LL developed the bioinformatic methodology, TM and AK performed the bioinformatic analysis, SN designed and established the plasmids used in this study, TM performed the activity screening and enzymatic characterization of PL-GOS, JB, and RK tested and evaluated enantioselectivity of PL-GOS, RK, and LL modeled the structure of PL-GOS, TM, and LL wrote the manuscript.

lipolytic activity on Escherichia coli. Appl. Environ. Microbiol. 66, 3113-3116. doi: 10.1128/AEM.66.7.3113-3116.2000

Jaeger, K. E., Dijkstra, B. W., and Reetz, M. T. (1999). Bacterial biocatalysts: molecular biology. Three-Dimensional Structures, and Biotechnological Applications of Lipases. Annu. Rev. Microbiol. 53, 315-351. doi: 10.1146/annurev.micro.53.1.315

Jaeger, K.-E., and Eggert, T. (2002). Lipases for biotechnology. Curr. Opin. Biotechnol. 13, 390-397. doi: 10.1016/S0958-1669(02)00341-5

Katoh, K., Misawa, K., Kuma, K.-I., and Miyata, T. (2002). MAFFT: a novel method for rapid multiple sequence alignment based on fast Fourier transform. Nucleic Acids Res. 30, 3059-3066. doi: 10.1093/nar/gkf436

Kelley, L. A., Mezulis, S., Yates, C. M., Wass, M. N., and Sternberg, M. J. E. (2015). The Phyre2 web portal for protein modeling, prediction and analysis. Nat. Protoc. 10, 845-858. doi: 10.1038/nprot.2015.053

Kourist, R., Domínguez de María, P., and Miyamoto, K. (2011). Biocatalytic strategies for the asymmetric synthesis of profens-recent trends and developments. Green Chem. 13, 2607-2618. doi: 10.1039/clgc15162b

Kuraku, S., Zmasek, C. M., Nishimura, O., and Katoh, K. (2013). Leaves facilitates on-demand exploration of metazoan gene family trees on MAFFT sequence alignment server with enhanced interactivity. Nucleic Acids Res. 41, W22-W28. doi: 10.1093/nar/gkt389

Lämmle, K., Zipper, H., Breuer, M., Hauer, B., Buta, C., Brunner, H., et al. (2007). Identification of novel enzymes with different hydrolytic activities by metagenome expression cloning. J. Biotechnol. 127, 575-592. doi: 10.1016/j.jbiotec.2006.07.036

Lee, M.-H., Lee, C.-H., Oh, T.-K., Song, J. K., and Yoon, J.-H. (2006). Isolation and characterization of a novel lipase from a metagenomic library of tidal flat sediments: evidence for a new family of bacterial lipases. Appl. Environ. Microbiol. 72, 7406-7409. doi: 10.1128/AEM.01157-06

Levisson, M., van der Oost, J., and Kengen, S. (2009). Carboxylic ester hydrolases from hyperthermophiles. Extremophiles 13, 567-581. doi: 10.1007/s00792-0090260-4

Li, Y., and Cirino, P. C. (2014). Recent advances in engineering proteins for biocatalysis. Biotechnol. Bioeng. 111, 1273-1287. doi: 10.1002/bit.25240

Lowe, M. E. (1992). The catalytic site residues and interfacial binding of human pancreatic lipase. J. Biol. Chem. 267, 17069-17073.

Mala, J. G. S., and Takeuchi, S. (2008). Understanding structural features of microbial lipases-an overview. Anal. Chem. Insights 3, 9-19.

Martínez-Martínez, M., Alcaide, M., Tchigvintsev, A., Reva, O., Polaina, J., Bargiela, R., et al. (2013). Biochemical diversity of carboxyl esterases and lipases from Lake Arreo (Spain): a metagenomic approach. Appl. Environ. Microbiol. 79, 3553-3562. doi: 10.1128/AEM.00240-13

Mokoena, N., Mathiba, K., Tsekoa, T., Steenkamp, P., and Rashamuse, K. (2013). Functional characterisation of a metagenome derived family VIII esterase with a deacetylation activity on $\beta$-lactam antibiotics. Biochem. Biophys. Res. Commun. 437, 342-348. doi: 10.1016/j.bbrc.2013.06.076

Nacke, H., Will, C., Herzog, S., Nowka, B., Engelhaupt, M., and Daniel, R. (2011). Identification of novel lipolytic genes and gene families by screening of metagenomic libraries derived from soil samples of the German Biodiversity 
Exploratories. FEMS Microbiol. Ecol. 78, 188-201. doi: 10.1111/j.15746941.2011.01088.x

Pleiss, J., Fischer, M., Peiker, M., Thiele, C., and Schmid, R. D. (2000). Lipase engineering database. J. Mol. Catal. B Enzym. 10, 491-508. doi: 10.1016/S13811177(00)00092-8

Qian, Z., and Lutz, S. (2005). Improving the catalytic activity of candida antarctica lipase b by circular permutation. Am. Chem. Soc. 127, 13466-13467. doi: 10.1021/ja053932h

Reetz, M. T., Bocola, M., Carballeira, J. D., Zha, D., and Vogel, A. (2005). Expanding the range of substrate acceptance of enzymes: combinatorial active-site saturation test. Angew. Chem. Int. Ed. Engl. 44, 4192-4196. doi: 10.1002/anie. 200500767

Rhee, J.-K., Ahn, D.-G., Kim, Y.-G., and Oh, J.-W. (2005). New thermophilic and thermostable esterase with sequence similarity to the hormone-sensitive lipase family, cloned from a metagenomic library. Appl. Environ. Microbiol. 71, 817-825. doi: 10.1128/AEM.71.2.817-825.2005

Rusch, D. B., Halpern, A. L., Sutton, G., Heidelberg, K. B., Williamson, S., Yooseph, S., et al. (2007). The sorcerer ii global ocean sampling expedition: northwest atlantic through eastern tropical pacific. PLoS Biol. 5:e77. doi: 10.1371/journal.pbio.0050077

Sharma, R., Chisti, Y., and Banerjee, U. C. (2001). Production, purification, characterization, and applications of lipases. Biotechnol. Adv. 19, 627-662. doi: 10.1016/S0734-9750(01)00086-6

Simon, C., and Daniel, R. (2011). Metagenomic analyses: past and future trends. Appl. Environ. Microbiol. 77, 1153-1161. doi: 10.1128/AEM.02345-10

Suen, W. C., Zhang, N., Xiao, L., Madison, V., and Zaks, A. (2004). Improved activity and thermostability of Candida antarctica lipase B by DNA family shuffling. Protein Eng. Des. Sel. 17, 133-140. doi: 10.1093/protein/gzh017

The Freedonia Group (2014). World Enzymes - Demand, and Sales Forecasts, Market Share, Market Size, Market Leaders (Cleveland, OH: The Freedonia Group Inc.), 338.

Tiesinga, J. J., van Pouderoyen, G., Nardini, M., Ransac, S., and Dijkstra, B. W. (2007). Structural basis of phospholipase activity of Staphylococcus hyicus lipase. J. Mol. Biol. 10, 447-456.
Tirawongsaroj, P., Sriprang, R., Harnpicharnchai, P., Thongaram, T., Champreda, V., Tanapongpipat, S., et al. (2008). Novel thermophilic and thermostable lipolytic enzymes from a Thailand hot spring metagenomic library. J. Biotechnol. 133, 42-49. doi: 10.1016/j.jbiotec.2007.08.046

Tringe, S. G., and Rubin, E. M. (2005). Metagenomics: DNA sequencing of environmental samples. Nat. Rev. Genet. 6, 805-814. doi: 10.1038/nrg1709

van Dongen, S., and Abreu-Goodger, C. (2011). "Using MCL to extract clusters from networks," in Bacterial Molecular Networks Methods in Molecular Biology, (New York, NY: Springer), 281-295.

Widersten, M. (2014). Protein engineering for development of new hydrolytic biocatalysts. Curr. Opin. Chem. Biol. 21, 42-47. doi: 10.1016/j.cbpa.2014.0 3.015

Widmann, M., Juhl, P. B., and Pleiss, J. (2010). Structural classification by the Lipase Engineering Database: a case study of Candida antarctica lipase A. BMC Genomics 11:123. doi: 10.1186/1471-2164-11-123

Yooseph, S., Sutton, G., Rusch, D. B., Halpern, A. L., Williamson, S. J., Remington, K., et al. (2007). The sorcerer ii global ocean sampling expedition: expanding the universe of protein families. PLoS Biol. 5:e16. doi: 10.1371/journal.pbio.0050016

Yu, S., Zheng, B., Zhao, X., and Feng, Y. (2010). Gene cloning and characterization of a novel thermophilic esterase from Fervidobacterium nodosum Rt17-B1. Acta Biochim. Biophys. Sin. (Shanghai) 42, 288-295. doi: 10.1093/abbs/gmq020

Conflict of Interest Statement: The authors declare that the research was conducted in the absence of any commercial or financial relationships that could be construed as a potential conflict of interest.

Copyright (C) 2015 Masuch, Kusnezowa, Nilewski, Bautista, Kourist and Leichert. This is an open-access article distributed under the terms of the Creative Commons Attribution License (CC BY). The use, distribution or reproduction in other forums is permitted, provided the original author(s) or licensor are credited and that the original publication in this journal is cited, in accordance with accepted academic practice. No use, distribution or reproduction is permitted which does not comply with these terms. 